\title{
Influence of gestational salt restriction in fetal growth and in development of diseases in adulthood
}

\author{
Hiroe Sakuyama', Minami Katoh ${ }^{1}$, Honoka Wakabayashi', Anthony Zulli ${ }^{1}$, Peter Kruzliak ${ }^{3,4^{*}}$ and Yoshio Uehara ${ }^{1}$
}

\begin{abstract}
Recent studies reported the critical role of the intrauterine environment of a fetus in growth or the development of disease in adulthood. In this article we discussed the implications of salt restriction in growth of a fetus and the development of growth-related disease in adulthood. Salt restriction causes retardation of fatal growth or intrauterine death thereby leading to low birth weight or decreased birth rate. Such retardation of growth along with the upregulation of the renin angiotensin system due to salt restriction results in the underdevelopment of cardiovascular organs or decreases the number of the nephron in the kidney and is responsible for onset of hypertension in adulthood. In addition, gestational salt restriction is associated with salt craving after weaning. Moreover, salt restriction is associated with a decrease in insulin sensitivity. A series of alterations in metabolism due to salt restriction are probably mediated by the upregulation of the renin angiotensin system and an epigenetic mechanism including proinflammatory substances or histone methylation. Part of the metabolic disease in adulthood may be programmed through such epigenetic changes. The modification of gene in a fetus may be switched on through environment factors or life style after birth. The benefits of salt restriction have been assumed thus far; however, more precise investigation is required of its influence on the health of fetuses and the onset of various diseases in adulthood.
\end{abstract}

Keywords: Salt restriction, Low birth weight, Low birth rate, Programing, Growth retardation, Hypertension, Salt sensitivity, Insulin resistance, Dyslipidemia

\section{Background}

Salt is an essential nutrient for all cells and a reduction in salt intake results in the collapse of cardiovascular circulation. Humans possess more salt-retaining systems, e.g., hemodynamic, hormonal and renin angiotensin systems than salt-excreting mechanisms. Therefore, an imbalance between salt intake and salt-retaining systems is believed to be responsible for the onset of cardiovascular disease in adulthood.

With regard to the intrauterine environment, however, the effects of salt intake by mothers on the fetal growth have not yet been addressed. In fact, the fetal mechanisms for coping with a low-salt environment or the impact of

\footnotetext{
* Correspondence: peter.kruzliak@savba.sk

${ }^{3}$ 2nd Department of Internal Medicine, Faculty of Medicine, Masaryk University, Pekarska 53, 65691 Brno, Czech Republic

${ }^{4}$ Laboratory of Structural Biology and Proteomics, Central Laboratories, Faculty of Pharmacy, University of Veterinary and Pharmaceutical Sciences, Brno, Czech Republic

Full list of author information is available at the end of the article
}

excessive salt restriction on the fetal growth and health have not been investigated. Given their intrauterine status, fetuses are more subject than adults to a low-salt environment and are influenced by salt restriction-related hemodynamic and hormonal alterations in their mothers as well as by their own homeostatic changes.

Recent studies have found an association between intrauterine growth retardation and cardiovascular dysfunction with structural changes in both animals and humans. In this sense, it would be intriguing to determine the pathophysiological role of maternal salt metabolism in the fetal growth and to examine whether growth retardation due to excessive salt restriction is associated with diseases in adulthood.

Accordingly, this review focuses on recent studies concerning the effects of excessive salt restriction on fetal growth and reviews the possible mechanism underling this risk. It is also within our scope to discuss the association of growth retardation due to salt restriction with 
hypertension and metabolic diseases in adulthood, with special reference to epigenetic and gene-related mechanisms.

\section{Salt restriction and excessive salt intake}

In the field of hypertension research, a salt intake of $6 \mathrm{~g}$ per day (equivalent to $2.4 \mathrm{~g}$ sodium) has long been recommended for hypertensive patients, regardless of the presence of or absence of diabetes or chronic kidney diseases [1]. However, the average salt intake worldwide is estimated to be approximately $9.87(5.45-13.77) \mathrm{g}$ per day according to public information [2]. The average salt intake in the United State is approximately $9 \mathrm{~g}$ per day, and less than $5 \%$ US of the population consumes less than $3.75 \mathrm{~g}$ per day [3]. In Japan, the estimated salt intake has remained at approximately $10-15 \mathrm{~g}$ per day for decades [4]. Salt intake depends on age, gender and ethnicity, and this likely explains the lack of consensus regarding defined amounts of sat indicative of restriction or excessive intake. In general, however, the target amount for salt restriction is less than $6 \mathrm{~g}$ per day, and 6-12 g per day is considered moderate or normal salt intake. A salt intake exceeding $12-15 \mathrm{~g}$ day might be considered a high-salt intake in clinical settings. Dietary Guidelines for Americans 2010 recommends a maximum dietary sodium intake of $2300 \mathrm{mg}$ per day for the general population, and the World Health Organization recommends 2000 mg of sodium; however, most Americans consume a higher level of sodium, according to data from the National Health and Nutrition Examination Survey [4]. In Canada, a daily salt intake of $3.75 \mathrm{~g}$ salt per day is recommended; however, an intake of less than $3 \mathrm{~g}$ per day has been unattainable thus far on a public population. Small clinical studies, however, have studied severe low-salt groups, defined as those with a salt intake of less than $1 \mathrm{~g}$ per day. Thus, the definition of salt restriction likely varies among studies, and in the present review we have attempted to specify the amount of salt whenever possible.

The findings from animal studies are much clear. The salt content in regular chow used for rodent colony maintenance is approximately $0.75 \%(\mathrm{w} / \mathrm{w})$. In the field of hypertension research, a low-salt diet contains $0.3 \%$ salt $(\mathrm{w} / \mathrm{w})$ and a no salt diet contains less than $0.1 \%$ salt $(\mathrm{w} / \mathrm{w})[5,6]$. In other words, animals fed a low-salt diet consume less than half of the usual salt intake. In studies using Dahl salt sensitive (Dahl S) rats, a high-salt diet is defined as containing 4 or $8 \%$ salt $(w / w)$, according to the definition given by the American Heart Association hypertension council [5, 6]. A Dahl S rat weighing $300 \mathrm{~g}$ usually consumes approximately $30 \mathrm{~g}$ chow per day, or approximately $0.3 \mathrm{~g}$ salt $/ \mathrm{kg} \mathrm{BW}$ per day for a $0.3 \%$ low-salt diet and $8 \mathrm{~g}$ salt $/ \mathrm{kg}$ BW per day for an $8 \%$ high-salt diet.
Moreover, there are notably no standard methods with which to assess salt intake in clinical settings. In small clinical studies, salt intake is accurately assessed by determining of the salt content of foods; however, in large population-based epidemiological studies, it is impossible to obtain $24 \mathrm{~h}$ urine samples to determine the urinary excretion of sodium as an index of salt intake. Thus, salt intake is usually estimated from interviews concerning ingested foods or via spot urine collection, which might result in variability in the reported amounts of salt intake in the literature $[7,8]$. Accordingly, in this review, we have provided information on the methods used to determine salt intake to the extent possible.

\section{Salt restriction and health risk in offspring}

For more than 50 years, the role of salt in health has been an important topic in the field of public health as well as in cardiovascular research. Increased salt intake has been implicated in hypertension and various other vascular diseases. Whether a lower salt intake is better for health from a public health standpoint has remained a matter of debate worldwide $[9,10]$. To our surprise, however, a recent meta-analysis of 25 previous studies on salt intake and an average 3.7-y observational study of 101,945 people in 17 countries wherein salt intake was assessed by determining urinary sodium excretion demonstrated an association between low-salt intake and an increase in cardiovascular events/death, compared with normal salt intake $[10,11]$. Graudal et al. reported that low sodium intake (less than $115 \mathrm{~mol}$ per day, equivalent to $6.67 \mathrm{~g}$ salt) and high sodium intake (more than $215 \mathrm{~mol}$ per day, equivalent to12.47 g salt ), relative to the usual sodium intake (115-215 mol per day, equivalent to $6.67-12.47 \mathrm{~g}$ salt), were both associated with increased mortality. There was no difference between low usual sodium intake (115-165 mol per day, equivalent to 6.67-9.57 g salt) and high usual sodium intake (165-215 mol per day, equivalent to $9.57-12.47 \mathrm{~g}$ salt). This is consistent with a J-shaped association between sodium intake and health outcomes [10]. Similarly, a daily sodium intake of 4-5.99 g, equivalent to $10-15 \mathrm{~g}$ salt, estimated on the basis of measured urinary excretion, was associated with a lower risk of death and cardiovascular events than either a higher ( $\geq 7.0 \mathrm{~g}$ sodium per day, $17.5 \mathrm{~g}$ salt) or lower salt intake ( $<3 \mathrm{~g}$ sodium per day, $7.5 \mathrm{~g}$ salt) [11]. These studies estimated an optimal salt intake of approximately $8-10 \mathrm{~g}$ salt per day. The mechanism by which low-salt intake confers this risk is unclear. However, it is noted that the benefits of blood pressure changes appear to be small because the blood pressure reduction due to salt restriction is slight in the range of moderate salt intake (7.5-12.5 g salt per day) [12]. On the other hand, renin angiotensin system is enhanced under conditions of salt restriction $(<3.0 \mathrm{~g}$ sodium per day, $7.5 \mathrm{~g}$ salt $)$ [11], and 
this presumably promotes cardiovascular and renal injury mechanisms independently of blood pressure. Despite such well-designed studies on salt and cardiovascular diseases in adulthood, few studies have addressed the role of gestational salt intake in the health of mothers and their neonates. Intriguingly, however, some studies suggest that a slight change in intrauterine circumstances influence fetal growth. In particular, intrauterine growth retardation (IUGR) due to salt restriction might be possibly related to the underdevelopment of cardiovascular or metabolic systems. An interesting hypothesis has been proposed that some forms of cardiovascular or metabolic diseases in adulthood are programmed during fetal growth in the mother's uterus.

\section{Impaired growth and gestational salt restriction}

Salt restriction is associated with low birth and survival rates and low birth weight. In an animal study, intake of low-salt $(0.3 \% \mathrm{NaCl}, \mathrm{w} / \mathrm{w})$ chow during mating and gestation is associated with low birth and survival rates of pups of Dahl salt-sensitive rat pups, compared with pups from mothers fed a high-salt $(4 \% \mathrm{NaCl}, \mathrm{w} / \mathrm{w})$ diet (Table 1) [13]. Low-salt intake during mating and pregnancy causes an approximately $50 \%$ decrease in birth rate, with a significantly lowered birth weight. These are the results of spontaneous abortion or impaired fetal growth due to salt restriction during pregnancy. The low-salt chow utilized is approximately $50 \%$ less salt than the regular chow $(0.75 \% \mathrm{NaCl}, \mathrm{w} / \mathrm{w})$ for maintaining a colony $[13,14]$. This suggests that moderate salt restriction during the perinatal period could be a risk to the normal intrauterine growth of a fetus.

Moreover, the pup survival rate during lactation was $95 \%$ for mothers on a high-salt diet during pregnancy, whereas it was as low as $64 \%$ for mothers on the low- salt $(0.3 \% \mathrm{NaCl}, \mathrm{w} / \mathrm{w})$ diet (Fig. 1) [13]. It is not clear whether this is related to behavior changes in mothers due to salt restriction or to babies that possibly have defects critical in intrauterine environments. As shown in Kaplan Meier analysis there are two types of death, i.e., death just after birth and that during normal growth of pups while taking milk. Since the death is associated with cannibalism, it is noted that the salt restriction could cause behavior changes in mothers. More precise investigation is needed. Moreover, de Siqueira et al. also reported that Wistar rats with a low-salt intake $(0.15 \%$ $\mathrm{NaCl}, \mathrm{w} / \mathrm{w})$ in the second half of gestation had low birth weight and size, thereby suggesting that the salt restriction $(0.15 \% \mathrm{NaCl}, \mathrm{w} / \mathrm{w})$ more likely affects the intrauterine development of the organs of fetuses than normal sodium diet $(1.3 \% \mathrm{NaCl}, \mathrm{w} / \mathrm{w})$ [15].

In humans, the direct evidence of the etiological association of gestational salt restriction and impaired growth of neonates is limited. Recently, however, there have been a growing number of studies supporting the hypothesis. Originally, it was reported that severe morning sickness and hyperemesis gravida is often associated with low birth weight or premature labor and the loss of salt resulting from vomiting is believed to be responsible for both the low birth rate and low birth weight [16-18]. Moreover, Shirazki et al. found that babies with low blood sodium concentrations resulting from their mother's low-salt intakes during pregnancy are more likely to be underweight at birth [19]. Salt restriction or mineralofluid loss due to vomiting in pregnancy influences physical status, and babies born of mothers with extracellular volume loss by polyethylene glycol more likely crave salt after birth $[19,20]$. Low-salt $(0.3 \% \mathrm{NaCl}, \mathrm{w} / \mathrm{w})$ solely during gestation is related to the increase of salt appetite in pups, but after birth the relation

Table 1 Number of mothers that delivered pups

\begin{tabular}{|c|c|c|c|c|c|c|c|c|}
\hline \multirow[t]{2}{*}{ Group } & \multicolumn{2}{|c|}{ Diet $(\mathrm{NaCl}, \mathrm{w} / \mathrm{w})$} & \multicolumn{3}{|c|}{ Mother (No) } & \multicolumn{3}{|c|}{ Statistics $^{a}$} \\
\hline & Mating & $\overline{\text { Pregnant }}$ & Total & Delivered** $^{* *}$ & Babies/Mother $^{b}$ & $\overline{x^{2}}$ & $p$ & VS \\
\hline MHPR & $4.0 \%$ & $0.75 \%$ & 7 & 7 & $7.4 \pm 2.3$ & & & \\
\hline MLPR & $0.3 \%$ & $0.75 \%$ & 7 & 4 & $8.7 \pm 1.7$ & 3.82 & 0.050 & MHPR \\
\hline \multirow[t]{4}{*}{ MRPR } & $0.75 \%$ & $0.75 \%$ & 8 & 7 & $8.2 \pm 1.4$ & 0.94 & 0.332 & MHPR \\
\hline & & & & & & 1.76 & 0.184 & MLPR \\
\hline & & & & & & 1.45 & 0.228 & $\mathrm{MRPH}$ \\
\hline & & & & & & 2.33 & 0.127 & MRPL \\
\hline MRPH & $0.75 \%$ & $4.0 \%$ & 11 & 11 & $10.2 \pm 1.3$ & & & \\
\hline MRPL & $0.75 \%$ & $0.3 \%$ & 11 & 6 & $8.8 \pm 3.0$ & 6.87 & 0.011 & $\mathrm{MRPH}$ \\
\hline
\end{tabular}

MHPR, mothers fed the high-salt ( $4 \% \mathrm{NaCl}, \mathrm{w} / \mathrm{w})$ diet during mating period and the regular $(0.75 \% \mathrm{NaCl}$, w/w) chow during pregnant period; MLPR, mothers fed the low-salt $(0.3 \% \mathrm{NaCl}, \mathrm{w} / \mathrm{w})$ diet during mating period and the regular chow during pregnant period; MRPR, mothers fed the regular chow during mating period and during pregnant period; $\mathrm{MRPH}$, mothers fed the regular chow during mating period and the high-salt diet pregnant period; MRPL, mothers fed the regular chow during mating period and the low-salt diet during pregnant period. Total, the total number of mothers; delivered, the number of mothers that gave birth to pups; non-delivered, the number of mothers that failed to give birth to pups. ${ }^{* *}$ The differences in delivered rats were assessed by $\mathrm{x}^{2}$ test $(\mathrm{df}=1) .0 .75 \% \mathrm{NaCl}(\mathrm{w} / \mathrm{w})$ chow (regular chow) is usually used for maintaining of rat colonies. ${ }^{b}$ mothers that delivered babies.

Cited from Chou R et al. Journal of Nutrition and Metabolism volume 2014. Article ID 212089, (ref\# [13]). 


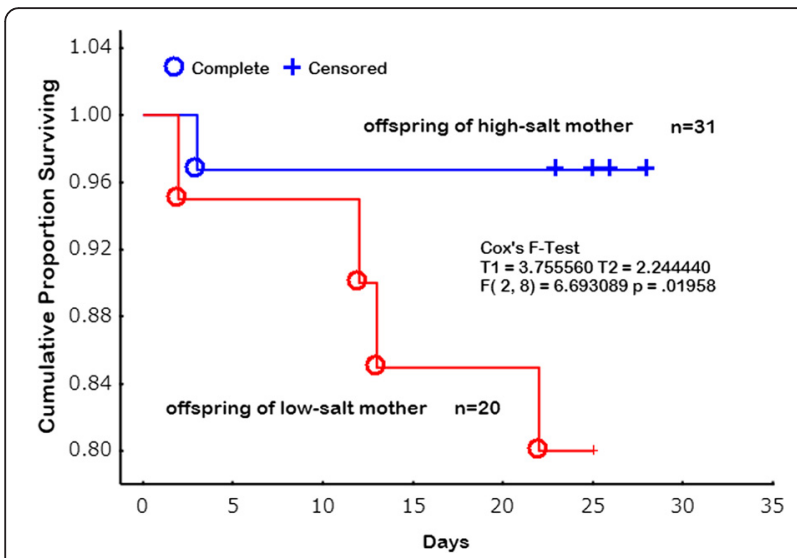

Fig. 1 Cumulative proportion of offspring survival (Kaplan Meier analysis). Survival prognosis was evaluated from their birth of the rat pups to weaning. Open circles refer to the death (complete) of pups from high-salt $(4 \% \mathrm{NaCl}, \mathrm{w} / \mathrm{w})$ intake mothers; solid circles refer to the (complete) of pups from a low-salt $(0.3 \% \mathrm{NaCl}, \mathrm{w} / \mathrm{w})$ intake mothers. plus ( + ), censor. The difference was analyzed by Cox's F-Test $(T 1=3.755$, $\mathrm{T} 2=2.244, \mathrm{~F}(2,8)=6.6930, p=0.01958)$. Cited from Chou R et al. $(2014)$ Journal of Nutrition and Metabolism volume 2014. Article ID 212089, (ref\# [13]).

disappears. Low-salt diet $(0.3 \% \mathrm{NaCl}, \mathrm{w} / \mathrm{w})$ in pregnancy caused craving for salt in pups compared with high-salt $(4 \% \mathrm{NaCl}, \mathrm{w} / \mathrm{w})$ mothers whereas after weaning, salt appetite increases in babies fed a highsalt $(4 \% \mathrm{NaCl}, \mathrm{w} / \mathrm{w})$ diet compared with those fed a low-salt $(0.3 \% \mathrm{NaCl}, \mathrm{w} / \mathrm{w})$ diet (Fig. 2) [21-23]. It is also known that in premature babies, physical and mental abilities are improved in children whose diets are supplemented with salt [24].

\section{Mechanism of impaired growth due to salt restriction}

The reasons for fewer or low-birth-weight pups being born of pregnant mothers with salt restrictions remain unclear. However, low birth weight in response to saltrestriction during pregnancy is due to alterations of uterine-placental perfusion [25]. It has also been reported that salt is critical for the development of the glial (immune) cells in the brain. In fact, it is reported that salt restriction of $0.022-0.04 \%$ sodium diet caused retardation of brain development in association with less consumption of diet, low weight and low survival rate during lactation in Sprague Dawley rats [26]. Infants with low sodium intake may experience poor neurological function in early adolescence, and low-salt intake impairs the normal development of the nerve sheath in a fetus. Growth inhibition of astrocytes in the neonate brain, which occurs because of low-salt intake during pregnancy, is possibly involved in the dysfunction of the autonomic system in adulthood, thereby affecting hemodynamic or metabolic changes in adulthood. Although this hypothesis is interesting, further clinical trials are required for validation.

Decreased renal blood flow due to low-salt intake usually enhances the activity of the renin angiotensin system, and the enhancement conceivably affects the intrauterine growth of infants of mothers with salt restrictions. In fact, the overexpression of the renin angiotensin system in transgenic mice causes a placenta-fetus imbalance and leads to pre-eclampsia [27-29]. The increase in angiotensin II due to salt restrictions is assumed to cause a placenta-fetus imbalance, and if so, it may result in low birth rate or low birth weight. Moreover, recent studies have reported an angiotensin IImediated epigenetic mechanism for disease expression or impaired kidney and organ growth during pregnancy [30-33]. Events that are triggered after a low-salt challenge, i.e., enhanced regulation of rein angiotensin system, are presumed to be involved in gene modification that become overt through influences after birth. Less than $3 \mathrm{~g}$ sodium/day is expected in general to trigger renin-angiotensin axis. Moreover, it is well reported that during critical developmental periods, salt restriction might affect fetal hormonal, vascular, and renal systems
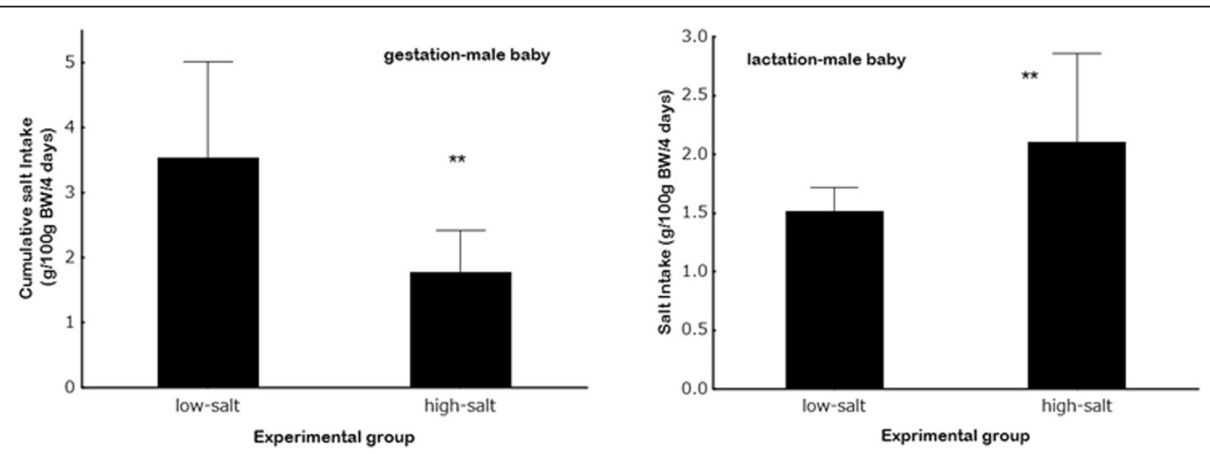

Fig. 2 Amounts of saline solutions in the male baby rats from low-and high-salt mothers during gestation and lactation. Cumulative salt intake for the 4-day in male baby rats from low- $(0.3 \% \mathrm{NaCl}, \mathrm{w} / \mathrm{w})$ and high-salt $(4 \% \mathrm{NaCl})$ mothers during gestation (left graph) and lactation period (right graph) ${ }^{* *} p<0.005$ vs the respective values of low-salt $(0.3 \% \mathrm{NaCl}, \mathrm{w} / \mathrm{w})$ mothers. Cited from Hara A et al. (2014) Food and Nutrition Sciences Vol.5 No.19, PP. 1904-1913 (ref\# [23]). 
to regulate fluid homeostasis in the fetus [34]. Both the neurohypophysial hormones arginine vasopressin and oxytocin participating in volume regulation in human pregnancy and modulating vascular tone are reported to be impaired in severe sodium (0.46 g/day) restriction [35]. Such hormonal response might contribute in part to the impaired growth or death in pups from mothers on low-salt diet. The details are to be discussed later.

\section{Gestational salt intake and adult hypertension}

Since Barker and investigators from other laboratories reported the association of birth weight and death due to ischemic heart disease [36], there has been a considerable amount of evidence in animal studies suggesting that low birth weight determines the onset of hypertension, insulin resistance and lipid dysfunction [37, 38]. The relationship has been consistently confirmed in humans as well [39-41]. Very large longitudinal study of 13,517 subjects born in Helsinki University Hospital between 1924 and 1944 clearly demonstrated that small size at birth and during infancy with accelerated weight gain from age 3 to 11 years predicts higher incidence of coronary heart diseases, type 2 diabetes and hypertension [42]. These diseases are integral components of metabolic syndrome, and it suggests that intrauterine process in such a low birth weight fetus programs the clustering of these disorders in adulthood.

Animal studies have provided some information on the mechanism that underlies the association. Recently, Benz and Amann reviewed the role of nephron development in the association of maternal nutrition and hypertension [43]. In humans, nephrogenesis occurs from weeks 5 to 36 of gestation, with the most critical period being the mid-second trimester until 36 weeks; fetuses are very sensitive to genetic and environmental factors such as maternal diet during this 16 -week period. This critical period is in accordance with the data from de Siqueira et al. suggesting low-salt intake in the second half of gestation is associated with low birth weight and size [15]. Such slight changes in intrauterine circumstance that cause low birth weight hamper normal kidney development $[44,45]$. A decreased number of nephrons could conceivably cause salt sensitivity and thereby developing hypertension in adult offspring. Indeed, Simonetti et al. found that children with growth-restriction have a risk for reduced renal mass as determined by ultrasound and increased salt sensitivity [46]. A decreased number of nephrons during gestational development or by acquired kidney diseases reduce the ability of nephrons to handle sodium excretion, which leads to the development of hypertension.

Moreover, salt-restriction during pregnancy enhances salt-craving in Dahl pups after weaning [13]. Saltrestriction $(0.3 \% \mathrm{NaCl}, \mathrm{w} / \mathrm{w})$ in gestation causes an increase in salt-appetite, but the taste of salt does not change. The association of salt-restriction with an increase in salt appetite is observed in both male and female pups. In contrast, high-salt $(4 \% \mathrm{NaCl}, \mathrm{w} / \mathrm{w})$ intake in mothers during lactation increases the salt appetite in the pups after weaning. Salt loss in pregnant rats resulting from polyethylene glycol intake which produces extracellular dehydration increases salt-appetite [21]. In humans it has been well documented that morning sickness and salt-loss due to hormonal dysfunction in neonates in turn enhances salt-appetite later in their babies [16-20]. Interestingly, Shirazki et al. clearly demonstrated that in low birth weight children, salt appetite in children aged 10 years old is negatively related to the neonatal serum sodium [20]. In general, in animals and in humans thirst and sodium appetite are programmed by the developmental environment [47]. Increased saltappetite and enhanced salt-sensitivity due to saltrestriction concurrently increase blood pressure [46]. It is well known that baby Dahl salt-sensitive pups are more sensitive to salt-loading than adult rats.

Salt-restriction decreases renal blood flow and triggers the secretion of renin from the kidney. The increased plasma renin concentrations initiate the breakdown of renin substrate, angiotensinogen, and finally, produce the octapeptide, angiotensin II. The upregulation of angiotensin II probably influences food preferences. In very young, normal female subjects, the consumption of total lipids, cholesterol, and unsaturated free fatty acids is higher in those with the MM/MT genotype of AGTMet235 [48]. In this context, some studies have been performed to postulate the role of intracerebral angiotensin II in water and salt drinking, and it is found that angiotensin II infusion in the cerebral fluid enhances behavior of drinking water and salt-appetite [49-51]. Salt-restriction evokes activity of the renin angiotensin system, and its upregulation due to salt-restriction during fetal growth might be associated with an increased salt-appetite. More directly, sodium depletion produced marked increases in the dam's plasma angiotensin II and aldosterone concentrations. During prenatal sodium depletion, the activation of the renin angiotensin system rather than the loss of sodium itself is responsible for the modified salt intake behavior [52].

Such changes in renin angiotensin system increases blood pressure through vasoconstriction, a decrease in sodium excretion in the kidney, enhanced adrenergic nervous system and remodeling of the cardiovascular structure [22]. There is a great deal of evidence suggesting that intrauterine growth retardation (IUGR) or preeclampsia is associated with an increase in angiotensin II and that renin angiotensin system plays a critical role in under-development of intrauterine growth [27, 53-57]. However, the relationship of renin angiotensin system and 
organ growth is somewhat controversial. An intact renin angiotensin system is necessary for kidney function, and genetic defects of renin angiotensin system are associated with kidney abnormalities [58-61]. More directly, suppression of renin angiotensin system by losartan shortly after birth is associated with a significantly lower nephron number with hypertension [62,63]. Taken together, alterations of the intrauterine environment might be associated with either suppression or overexpression of components of the renin angiotensin system which then potentially contribute to hypertension by interfering with nephrogenesis.

\section{Salt restriction and insulin resistance}

An increasing amount of evidence has suggested that the programming occurring during gestation may play an important role in the development of metabolismrelated disorders during adulthood in humans [64-66]. Low birth weight resulting from salt restriction during pregnancy influences insulin sensitivity and dyslipidemia. Animal studies have demonstrated that lower glucose uptake and higher plasma cholesterol and triacylglycerol concentrations were observed in offspring of saltrestricted $(0.15 \% \mathrm{NaCl}, \mathrm{w} / \mathrm{w})$ Wistar rat dams than those in offspring from mothers fed a normal-salt (1.5\% $\mathrm{NaCl}, \mathrm{w} / \mathrm{w})$ diet [38]. Vidonho et al. reported that salt restriction $(0.15 \% \mathrm{NaCl}, \mathrm{w} / \mathrm{w})$ during pregnancy and lactation in Wistar rat dams decreases glucose uptake and insulin sensitivity in offspring determined by the glucose clamp method than high $(4$ or $8 \% \mathrm{NaCl}, \mathrm{w} / \mathrm{w})$ or normal $(1.3 \% \mathrm{NaCl}, \mathrm{w} / \mathrm{w})$ salt diet [37]. This was accompanied by higher plasma cholesterol and triacylglycerol concentrations. However, blood pressure was not necessarily increased in offspring of low-salt $(0.15 \%$ $\mathrm{NaCl}, \mathrm{w} / \mathrm{w})$ dams, which may be related in part to a different salt appetite in response to salt restriction $(0.3 \%$ $\mathrm{NaCl}, \mathrm{w} / \mathrm{w}$ ) during pregnancy and lactation periods as demonstrated in our previous study [13]. The sensitivity to salt intake may differ according to growth stage, i.e., intrauterine, lactation and after weaning. Unfortunately, there have been few studies thus far that discuss the effects of salt in the respective life stage. In this sense, we will have to wait to determine the exact relationship between salt intake and effects in adulthood. Despite such limitations, it has been noted that salt restriction in pregnant mothers or chronic salt restriction in both animals and humans is associated with decreased glucose uptake and insulin sensitivity.

\section{Renin angiotensin system and insulin sensitivity}

The association of salt restriction to a decrease in insulin sensitivity is explained to some extent by the enhancement of renin angiotensin system following chronic salt restriction. It has been well established in hypertension research field that enhanced activity of renin angiotensin system facilitates adrenergic nervous activity in animals and humans [22, 67]. Upregulation of the $\alpha$-adrenergic nervous system increases sodium reabsorption in renal tubules and induces vasoconstriction, both of which increase blood pressure $[68,69]$. Vasoconstriction by $\alpha$ stimulation reduces blood flow in the muscles and $\beta_{3}$ adrenoceptor stimulation increases lipolysis and gluconeogenesis, thereby mediating type-2 diabetes [70-72]. In this context, Ruivo et al. demonstrated using rats that $\alpha$ - and $\beta$-adrenoceptor blockades or L-arginine, improves glucose uptake as determined by the glucose clamp method, thereby increasing insulin sensitivity [73]. Low birth weight children show an increased heart rate with enhanced catecholamines and associated with sympathoadrenal overactivity after birth [74]. Because there are a bunch of studies suggesting that renin angiotensin system underlies the onset of the metabolic syndrome in adulthood, it is quite interesting that renin angiotensin system mediates the association of salt restriction during pregnancy with a decrease in insulin sensitivity in adulthood [75-77]. However, it is not clear whether renin angiotensin system is enhanced in intrauterine fetuses in saltrestricted mothers or if angiotensin II from mothers affects fetal growth through placental blood flow.

\section{Mechanism of insulin resistance by salt restriction}

Renin angiotensin system evokes proinflammatory cytokines, i.e. tumor necrotizing factor (TNF)- $\alpha$ and enhances oxygen stress through NADPH oxidase activation [78-83]. The proinflammatory cytokines, i.e. TNF- $\alpha$, interleukin (IL)-1 $\beta$, IL- 6 and resistin, and nitric oxide (NO) all act on adipocytes to induce an insulin-resistant state [78]. The alterations of subcellular signal transduction in insulin resistance have been extensively investigated. Salt restriction conceivably induces proinflammatory cytokines-mediated insulin resistance through upregulated renin angiotensin system; however, few articles thus far discussed subcellular signal transduction due to salt restriction. A recent study has found that high-salt ( $3.12 \%$ sodium, w/w, equivalent to $7.8 \%$ salt) diet increases insulin sensitivity in Wistar rats with increased GLUT4 gene expression, and increased insulin signaling, whereas low-salt $(0.06 \%$ sodium, w/w, equivalent to $0.15 \%$ salt) diet decreases insulin sensitivity with impaired insulin signaling [84]. Moreover, Prada et al. reported that the association of severe salt restriction $(0.15 \% \mathrm{NaCl}$ vs high-salt $1.25 \% \mathrm{NaCl}$ diet $)$ and insulin resistance and obesity is attributable to c-jun N-terminal kinase activity [85]. The kinase is involved in the pathophysiology of obesity and induces insulin resistance by increasing inhibitory IRS-1 $1^{\text {ser307 }}$ phosphorylation. This demonstrated that salt restriction increases c-jun $\mathrm{N}$ terminal kinase activity and IRS-1 ${ }^{\text {ser307 }}$ phosphorylation, thereby increasing body weight, visceral adiposity, and blood glucose and insulin levels with insulin resistance. 


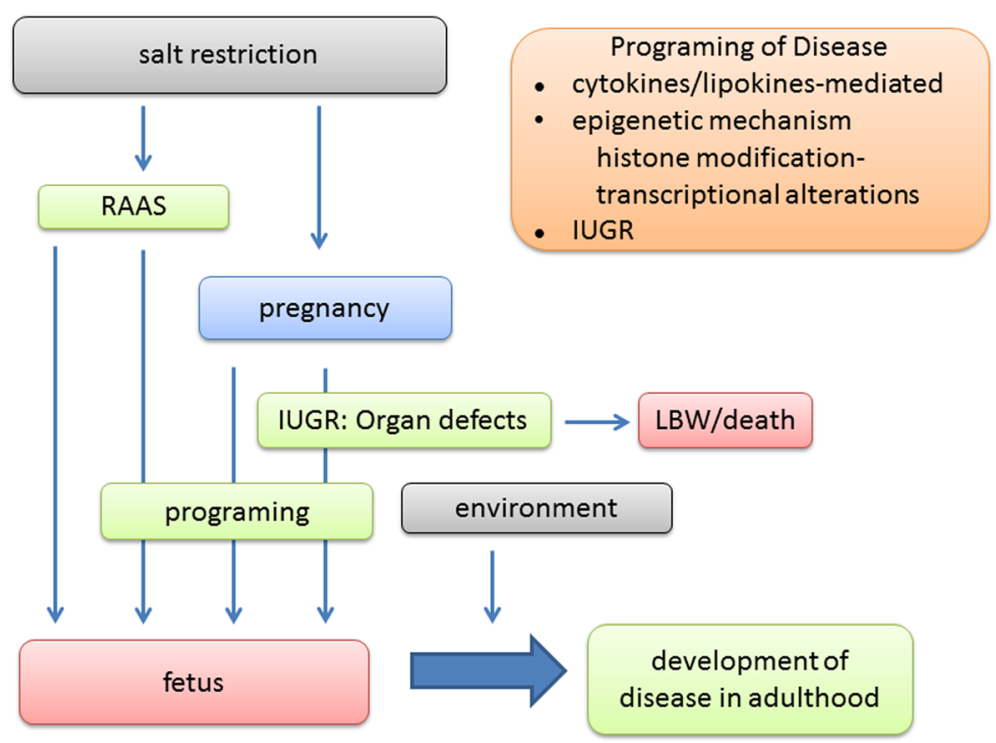

Fig. 3 Prospective mechanism for development of disease in adulthood. RAAS, renin angiotensin aldosterone system; IUGR, intrauterine growth retardation; LBW, low birth weight.

\section{Epigenetics and salt restriction}

Epigenetics, the variations in DNA methylation patterns and chromatin remodeling, provide an intriguing explanation for how environmental factors or intrauterine nutrition modify the risk for developing metabolic diseases in adulthood. However, there are limited data on the influence of early nutrition on epigenetics modifications [86]. One example of an epigenetic mechanism is that uteroplacental insufficiency-induced intrauterine growth restriction (IUGR), which predisposes to adult-onset insulin resistance, decreases postnatal insulin-like growth factor-1 (IGF-1) mRNA variants and the gene elongation mark histone 3 trimethylation of lysine 36 of the IGF-1 gene (H3Me3K36). H3M e3K36 is sensitive to the prenatal environment's glucose level with resultant alteration of IGF-1 mRNA expression and ultimately vulnerability to adult-onset insulin resistance [87-89].

The epigenetic mechanism is very promising for explaining the role of salt restriction in developing insulin resistance in adulthood. It has not been proven whether the enhanced activity of renin angiotensin system due to salt restriction mediates indeed the epigenetic mechanism. Moreover, if epigenetic DNA modifications occur, there have been few studies thus far on phenotype expression resulting from the epigenetic changes. Renin angiotensin system enhances proinflammatory cytokines or oxygen stress and nFkB-related transcriptional process [81, 83, 90-92]. In this sense it seems quite interesting to define whether angiotensin II participates in epigenetic mechanism with alterations of oxygen stress. Taken together, the epigenetic hypothesis promises to explain the late onset of diseases in adulthood.
However, the studies are in their infancy, and the implications of epigenetic involvement in phenotypic alterations in adulthood due to salt restriction in pregnant mothers remain to be elucidated.

\section{Conclusions}

Excess salt intake is believed to be a human health risk, however, recent studies have drawn attention to the role of intrauterine environment of fetuses in growth of babies and development of diseases in adulthood. There has been an increasing number of studies suggesting that salt restriction during pregnancy has a critical influence on the intrauterine growth and development of organs of fetuses and probably switches on important factors involved in the onset of adult-type diseases through anatomical changes and hemodynamic or hormonal control including intracellular signal transduction and gene modification. These links are illustrated in Fig. 3. Salt is one of the integral components for normal growth of fetuses. Salt restriction during pregnancy is connected to IURD or death, low birth weight, organ underdevelopment and dysfunction in adulthood probably through gene-mediated mechanism. Currently, the hypothesis appears more complicated, yet, understanding the mechanisms that program fetuses that leads to adult diseases is expected to provide a new insight for pathogenesis of cardiovascular and metabolic diseases.

Competing interest

The authors declare that they have no competing interests. 


\section{Author's contributions}

HS wrote the review. MK and HW collected the references for the review to be cited. AZ and PK checked scientific contents, revised the paper for important intellectual content and were responsible for manuscript in English. YU designed the review and managed all the process of the review writing. All authors read and approved the final manuscript.

\section{Author details}

'Division of Clinical Nutrition, Faculty of Home Economics, Kyoritsu Women's University, 2-2-1 Hitotsubashi, Chiyoda, Tokyo 101-8437, Japan. ${ }^{2}$ The Centre for Chronic Disease Prevention \& Management (CCDPM), Western CHRE, Victoria University, St Albans, Australia. ${ }^{3}$ 2nd Department of Internal Medicine, Faculty of Medicine, Masaryk University, Pekarska 53, 65691 Brno, Czech Republic. ${ }^{4}$ Laboratory of Structural Biology and Proteomics, Central Laboratories, Faculty of Pharmacy, University of Veterinary and Pharmaceutical Sciences, Brno, Czech Republic.

Received: 24 July 2015 Accepted: 12 January 2016

Published: 20 January 2016

\section{References}

1. Raymond R, Townsend RR, Wilkinson IB, Schiffrin EL, Avolio AP, Chirinos JA et al. Recommendations for Improving and Standardizing Vascular Research on Arterial Stiffness: A Scientific Statement From the American Heart Association. Hypertension. 2015;66:698-722.

2. Mozaffarian D, Fahimi S, Singh GM, Micha R, Khatibzadeh S, Engell RE, et al. Global Burden of Diseases Nutrition and Chronic Diseases Expert Group. Global sodium consumption and death from cardiovascular causes. N Engl J Med. 2014:371:624-34.

3. Fulgoni VL, Agarwal S, Lisa Spence L, Samuel P. Sodium intake in US ethnic subgroups and potential impact of a new sodium reduction technology: NHANES Dietary Modeling. Nutr J. 2014;13:120

4. The Salt Industry Center of Japan. Trends of salt intake in Japan (in Japanese). http://www.shiojigyo.com/a080data/img/sessyuryou24.pdf

5. Rapp JP. Dahl salt-susceptible and salt-resistant rats. Hypertension. 1982;4:753-63

6. Dahl LK. Effects of chronic excessive salt feeding. Induction of self sustaining hypertension in rats. J Exp Med. 1961;114:231-6.

7. McLean R, Williams S, Mann J. Monitoring population sodium intake using spot urine samples: validation in a New Zealand population. J Hum Hypertens. 2014;28:657-62.

8. Hawkes C, Webster J. National Approaches to Monitoring Population Salt Intake: A Trade-Off between Accuracy and Practicality? PLOS one. 2012;7, e46727.

9. Mente $\mathrm{A}, \mathrm{O}$ 'Donnell $\mathrm{M}$, Yusuf $\mathrm{S}$. Extreme sodium reductions for the entire population: Zealotry or Evidence Based? Am J Hypertens. 2013;26:1187-90

10. Graudal N, Jurgens G, Baslund B, Alderman MH. Compared with usual sodium intake, low- and excessive-sodium diets are associated with increased mortality: a meta-analysis. Am J Hypertens. 2014;27:1129-37.

11. O'Donnell M, Mente A, Rangarajan S, McQueen MJ, Wang X, Liu L, et al. Urinary sodium and potassium excretion, mortality, and cardiovascular events. N Engl J Med. 2014;371:612-23.

12. Mente A, O'Donnell MJ, Rangarajan S, McQueen MJ, Poirier P, Wielgosz A, et al. Association of urinary sodium and potassium excretion with blood pressure. N Engl J Med. 2014;371:601-11.

13. Chou R, Hara A, Du DD, Shimizu N, Sakuyama H, Uehara Y. Low salt intake during pregnancy is associated with low birth rate and low survival rate in rats with salt-sensitivity. J Nutr Met. Volume 2014. Article ID 212089, 5 pages. doi:10.1155/2014/212089

14. Feeds for laboratory animals. Bioresearch Services by Oriental Yeast Co., Ltd. Tokyo, Japan; 2011

15. de Siqueira FR, de Souza RM, de Oliveira IB, Furukawa LNS, Heimann JC. Low sodium intake is associated with low birth weight and size only when given in the second half of gestation. The FASEB J. 2012;26:712.4.

16. Crystal SR, Bernstein IL. Morning sickness: impact on offspring salt preference. Appetite. 1995;25:231-40.

17. Crystal SR, Bowen DJ, Bernstein IL. Morning sickness and salt intake, food cravings, and food aversions. Physiol Behav. 1996;67:181-7.

18. Crystal SR, Bernstein IL. Infant salt preference and mother's morning sickness. Appetite. 1998;30:297-307.
19. Shirazki A, Weintraub Z, Reich D, Gershon E, Leshem M. Lowest neonatal serum sodium predicts sodium intake in low birth weight children. Am J Physiol Regul Integr Comp Physiol. 2007;292:R1683-9.

20. Leshem M. Salt preference in adolescence is predicted by common prenatal and infantile mineralofluid loss. Physiol Behav. 1998;63:699-704.

21. Nicolaidis S, Galaverna O, Metzler CH. Extracellular dehydration during pregnancy increases salt appetite of offspring. Am J Physiol. 1990;258:R281-3.

22. Galaverna O, Nicolaïdis S, Yao SZ, Sakai RR, Epstein AN. Endocrine consequences of prenatal sodium depletion prepare rats for high need-free $\mathrm{NaCl}$ intake in adulthood. Am J Physiol. 1995;269:R578-83.

23. Hara A, Chou R, Sakuyama H, Du DD, Uehara Y. Low salt diet in pregnant mothers is associated with enhanced salt appetite in their offspring of Dahl salt-sensitive rats. Food Nutr Sci. 2014;5:1904-13.

24. Kresser C. Why low-salt diets are dangerous during pregnancy. http:// healthybabycode.com/why-low-salt-diets-are-dangerous-during-pregnancy. Low-salt diet increases insulin resistance in healthy subjects. 2015 March.

25. Leandro SM, Furukawa LNS, Shimizu MHM, Casarini DE, Seguro AC, Patriarca $\mathrm{G}$, et al. Low birth weight in response to salt restriction during pregnancy is not due to alterations in uterine-placental blood flow or the placental and peripheral renin-angiotensin system. Physiol Behav. 2008;95:145-51.

26. Bursey $\mathrm{RG}$, Watson $\mathrm{ML}$. The effect of sodium restriction during gestation on offspring brain development in rat. Am J Clin Nutr. 1983;37:43-51.

27. Brosnihan KB, Hering L, Dechend R, Chappell MC, Herse F. Increased angiotensin II in the mesometrial triangle of a transgenic rat model of preeclampsia. Hypertension. 2010;55:562-6.

28. Anton L, Merrill DC, Neves LA, Diz D, Corthorn J, Valdes G, et al. The uterine placental bed renin-angiotensin system in normal and preeclamptic pregnancy. Endocrinology. 2009;150:4316-25.

29. Shah DM. The role of RAS in the pathogenesis of preeclampsia. Curr Hypertens Rep. 2006;8:144-52.

30. Kato M, Natarajan R. Diabetic nephropathy-emerging epigenetic mechanisms. Nat Rev Nephrol. 2014;10:517-30.

31. Song R, Van Buren T, Yosypiv IV. Histone deacetylases are critical regulators of the renin-angiotensin system during ureteric bud branching morphogenesis. Pediatr Res. 2010;67:573-8.

32. Goyal R, Goyal D, Leitzke A, Gheorghe CP, Longo LD. Brain reninangiotensin system: fetal epigenetic programming by maternal protein restriction during pregnancy. Reprod Sci. 2010;17:227-38.

33. Reddy MA, Sumanth $\mathrm{P}$, Lanting L, Yuan $\mathrm{H}$, Wang M, Mar D, et al. Losartan reverses permissive epigenetic changes in renal glomeruli of diabetic $\mathrm{db} / \mathrm{db}$ mice. Kidney Int. 2014;85:362-73.

34. Guan J, Mao C, Feng X, Zhang H, Xu F, Geng C, et al. Fetal development of regulatory mechanisms for body fluid homeostasis. Brazil J Med Biol Res. 2008:41:446-54

35. van der Post JAM, van Buul BJA, Hart AAM, van Heerikhuize JJ, Pesman G, Legros JJ, et al. Vasopressin and oxytocin levels during normal pregnancy: effects of chronic dietary sodium restriction. J Endocrinol. 1997;152:345-54.

36. Barker DJP, Osmond C, Winter PD, Margetts B, Simmonds SJ. Weight in infancy and death from ischemic heart disease. Lancet. 1989;2:577-80.

37. Vidonho Jr AF, da Silva AA, Catanozi S, Rocha JC, Beutel A, Carillo BA, et al. Perinatal salt restriction: a new pathway to programming insulin resistance and dyslipidemia in adult Wistar rats. Pediatr Res. 2004;56:842-8.

38. Lopes KL, Furukawa LNS, de Oliveira IB, Dolnikoff MS, Heimann JC. Perinatal salt restriction: a new pathway to programming adiposity indices in adult female Wistar rats. Life Sci. 2008;82:728-32.

39. Dalziel SR, Parag V, Rodgers A, Harding JE. Cardiovascular risk factors at age 30 following preterm birth. Int J Epidemiol. 2007;36:907-15.

40. Uiterwaal CS, Anthony S, Launer L, Witteman JC, Trouwborst AM, Hofman A, et al. Birth weight, growth, and blood pressure: an annual follow-up study of children aged 5 through 21 years. Hypertension. 1997;30:267-71.

41. Adair L, Dahly D. Developmental determinants of blood pressure in adults. Annu Rev Nutr. 2005;25:407-34.

42. Barker DJP, Eriksson JG, Forsen T, Osmond C. Fetal origins of adult disease: strength of effects and biological basis. Int J Epidemiol. 2002;31:1235-9.

43. Benz K. Amann K. Maternal nutrition, low nephron number and arterial hypertension in later life. Biochim Biophys Acta. 1802;2010:1309-17.

44. Moritz KM, Mazzuca MQ, Siebel AL, Mibus A, Arena D, Tare M, et al. Uteroplacntal insufficieny causes a nephron deficit, modest renal insufficiency but no hypertension with ageing in female rats. J Physiol. 2009; 587:2635-46. 
45. Baum M. Role of the kidney in the prenatal and early postnatal programing of hypertension. Am J Physiol Renal Physiol. 2010;298:F235-7.

46. Simonnetti GD, Raio L, Surbek D, Nelle M, Frey FJ, Mohaupt MG. Salt sensitivity of children with low birth weight. Hypertension. 2008;52:625-30

47. Mecawia AS, Macchionec AF, Nuñeze P, Perillane C, Reisa LC, Vivasc L, et al. Arguellese J. Developmental programing of thirst and sodium appetite. Neurosci Biobehav Rev. 2015;51:1-14.

48. Sasaki M, Yamada K, Namba H, Yoshinaga M, Du D, Uehara Y. Angiotensinogen gene polymorphisms and food-intake behavior in young, normal female subjects in Japan. Nutrition. 2013;29:60-5.

49. Yang W, Mao C, Xia F, Zheng A, Zhu L, He R, et al. Changed salt appetite and central angiotensin II-induced cellular activation in rat offspring following hypoxia during fetal stages. Peptides. 2010;31:1177-83.

50. Nakano-Tateno T, Shichiri M, Suzuki-Kemuriyama N, Tani Y, Izumiyama H, Hirata Y. Prolonged effects of intracerebroventricular angiotensin II on drinking, eating and locomotor behavior in mice. Regul Peptides. 2012;173:86-92.

51. Mecawi AS, Araujo IG, Rocha FF, Coimbra TM, Antunes-Rodrigues J, Reis LC. Ontogenetic role of angiotensin-converting enzyme in rats: thirst and sodium appetite evaluation. Physiol Behav. 2010;99:118-24.

52. Bader M. Tissue renin-angiotensin-aldosterone systems: targets for pharmacological therapy. Annu Rev Pharmacol Toxicol. 2010;50:439-65.

53. Kingdom JC, Hayes M, McQueen J, Howatson AG, Lindop GB. Intrauterine growth restriction is associated with persistent juxtamedullary expression of renin in the fetal kidney. Kidney Int. 1999;55:424-9.

54. Kingdom JC, McQueen J, Connell JM, Whittle MJ. Fetal angiotensin II levels and vascular (type I) angiotensin receptors in pregnancies complicated by intrauterine growth retardation. Br J Obstet Gynaecol. 1993;100:476-82.

55. Antoes L, Merrill DC, Neves LAA, Diz DI, Corthorn J, Valdes G, et al. The uterine placental bed renin-angiotensin system in normal and preeclamptic pregnancy. Endocrinology. 2009;150:4316-25.

56. Shah DM. The role of RAS in the pathogenesis of preeclampsia. Curr Hypetens Rep. 2006:8:144-52.

57. Svitok P, Molcan L, Vesela A, Kruzliak P, Moravcik R, Zeman M. Increased salt intake during early ontogenesis lead to development of arterial hypertension in salt-resistant Wistar rats. Clin Exp Hypertens. 2015;37:142-7.

58. Lumbers ER. Functions of the renin-angiotensin system during development. Clin Exp Pharm Physiol. 1995;22:499-505.

59. Tabacova SA, Kimmel CA. Enalapril: pharmacokinetic/dynamic inferences for comparative developmental toxicity. A review Reprod Toxicol. 2001;15:467-78.

60. Vehaskari VM, Aviles DH, Manning J. Prenatal programming of adult hypertension in the rat. Kidney Int. 2001;59:238-45.

61. Matsusaka T, Miyazaki Y, Ichikawa I. The renin angiotensin system and kidney development. Annu Rev Physiol. 2002;64:551-61.

62. Woods LL. Fetal origins of adult hypertension: a renal mechanism? Curr Opin Nephrol Hypertens. 2000;9:419-25.

63. Garg R, Williams GH, Hurwitz S, Brown NJ, Hopkins PN, Adler GK. Low-salt diet increases insulin resistance in healthy subjects. Metabolism. 2011;60:965-8.

64. Klimas J, Olvedy M, Ochodnicka-Mackovicova K, Kruzliak P, Cacanyiova S, Kristek $F$, et al. Perinatally administered losartan augments renal ACE2 expression but not cardiac or renal Mas receptor in spontaneously hypertensive rats. J Cell Mol Med. 2015;19:1965-74

65. Rotteveel J, van Weissenbruch MM, Twisk JW. Delemarre-Van de Waal HA. Infant and childhood growth patterns, insulin sensitivity, and blood pressure in prematurely born young adults. Pediatrics. 2008;122:313-21.

66. Hovi P, Andersson S, Eriksso JG, Järvenpää AL, Strang-Karlsson S, Mäkitie O, et al. Glucose regulation in young adults with very low birth weight. N Engl J Med. 2007;356:2053-63.

67. Reid IA, Morris BJ, Ganong WF. The Renin-Angiotensin System. Annu Rev Physiol. 1978:40:377-410

68. Güllner HG. Regulation of sodium and water excretion by catecholamines. Life Sci. 1983;32:921-5.

69. Gesek FA. Stimulation of alpha 2-adrenergic receptors increases $\mathrm{Na}(+)$ $\mathrm{K}(+)$-ATPase activity in distal convoluted tubule cells. Am J Physiol. 1993:265:F561-8.

70. Lönnqvist F, Thöme A, Nilsell K, Hoffstedt J, Arner PJ. A pathogenic role of visceral fat beta 3-adrenoceptors in obesity. Clin Invest. 1995;95:1109-16.

71. Sakane N, Yoshida T, Umekawa T, Kondo M, Sakai Y, Takahashi T. Beta 3adrenergic-receptor polymorphism: a genetic marker for visceral fat obesity and the insulin resistance syndrome. Diabetologia. 1997;40:200-4.
72. García-Rubi E, Calles-Escandón J. Insulin resistance and type 2 diabetes mellitus: its relationship with the beta 3-adrenergic receptor. Arch Med Res. 1999;30:459-64

73. Ruivo GF, Leandro SM, do Nascimento CA, Catanozi S, Rocha JC, Furukawa $L N$, et al. Insulin resistance due to chronic salt restriction is corrected by alpha and beta blockade and by L-arginine. Physiol Behav. 2006:88:364-70.

74. Johansson S, Norman M, Legnevall L, Dalmaz Y, Lagercrantz H, Vanpée $M$. Increased catecholamines and heart rate in children with low birth weight: perinatal contributions to sympathoadrenal overactivity. J Intern Med. 2007:261:480-7.

75. Kamide K. Role of renin-angiotensin-aldosterone system in metabolic syndrome and obesity-related hypertension. Curr Hypertens Rev. 2014;9:238-45

76. Frigolet ME, Torres $\mathrm{N}$, Tovar AR. The renin-angiotensin system in adipose tissue and its metabolic consequences during obesity. J Nutr Biochem. 2013;24:2003-15.

77. de Kloet AD, Krause EG, Woods SC. The renin angiotensin system and the metabolic syndrome. Physiol Behav. 2010;100:525-34.

78. Olefsky JM, Glass CK. Macrophages, inflammation, and insulin resistance. Ann Rev Physiol. 2010;72:219-46.

79. Blüher M, Kratzsch J, Paschke R. Plasma levels of tumor necrosis factor-alpha, angiotensin II, growth hormone, and IGF-I are not elevated in insulinresistant obese individuals with impaired glucose tolerance. Diabetes Care. 2001;24:328-34.

80. de Vinuesa SG, Goicoechea M, Kanter J, Puerta M, Cachofeiro V, Lahera V, et al. Insulin resistance, inflammatory biomarkers, and adipokines in patients with chronic kidney disease: effects of angiotensin II blockade. J Am Soc Nephrol. 2006;17:S206-12.

81. Wei Y, Sowers JR, Clark SE, Li W, Ferrario CM, Stump CS. Angiotensin IIinduced skeletal muscle insulin resistance mediated by NF-kappaB activation via NADPH oxidase. Am J Physiol Endocrinol Metab. 2008:294:E345-51

82. Fasshauer M, Klein J, Neumann S, Eszlinger M, Paschke R. Tumor necrosis factor alpha is a negative regulator of resistin gene expression and secretion in 3T3-L1 adipocytes. Biochem Biophys Res Commun. 2001:288:1027-31.

83. Fortuño A, Bidegain J, Robador PA, Hermida J, López-Sagaseta J, Beloqui O, et al. Losartan metabolite EXP3179 blocks NADPH oxidase-mediated superoxide production by inhibiting protein kinase C: potential clinical implications in hypertension. Hypertension. 2009:54:744-50.

84. Okamoto MM, Sumida DH, Carvaho CRO, Vargas AM, Heimann JC, Schaan BDA, et al. Changes in dietary sodium consumption modulate GLUT4 gene expression and early steps of insulin signaling. Am J Physiol Regul Integr Comp Physiol. 2004:286:R779-85.

85. Prada PO, Coelho MS, Zecchin HG, Dolnikoff MS, Gasparetti AL, Furukawa LN, et al. Low salt intake modulates insulin signaling, JNK activity and IRS-1 ${ }^{\text {ser307 }}$ phosphorylation in rat tissues. J Endocrinol. 2005;185:429-37.

86. Liotto N, Miozzo M, Giannì ML, Taroni F, Morlacchi L, Piemontese P, et al. Early nutrition: the role of genetics and epigenetics. Pediatr Med Chir. 2009:31:65-71.

87. Zinkhan EK, Fu Q, Wang Y, Yu X, Callaway CW, Segar JL, et al. Maternal hyperglycemia disrupts histone 3 lysine 36 trimethylation of the IGF-1 gGene. J Nutr Metab. 2012;2012:930364.

88. Fu Q, McKnight RA, Callaway CW, Yu X, Lane RH, Majnik AV. Intrauterine growth restriction disrupts developmental epigenetics around distal growth hormone response elements on the rat hepatic IGF-1 gene. FASEB J. 2015: 29:1176-84.

89. Fu Q, Yu X, Callaway CW, Lane RH, McKnight RA. Epigenetics: intrauterine growth retardation (IUGR) modifies the histone code along the rat hepatic IGF-1 gene. FASEB J. 2009;23:2438-49.

90. Touyz RM, Tabet F, Schiffrin EL. Redox-dependent signalling by angiotensin II and vascular remodeling in hypertension. Clin Exp Pharmacol Physiol. 2003:30:860-6.

91. Touyz RM, Yao G, Viel E, Amiri F, Schiffrin EL. Angiotensin II and endothelin1 regulate MAP kinases through different redox-dependent mechanisms in human vascular smooth muscle cells. J Hypertens. 2004;22:1141-9.

92. Paravicini TM, Touyz RM. Redox signaling in hypertension. Cardiovasc Res. 2006;1:247-58. 